\title{
LAYOUT EM UMA FÁBRICA DE CAFÉ ESPECIAL: PROPOSTA DE APLICAÇÃO DO MÉTODO SLP
}

\section{LAYOUT IN A SPECIAL COFFEE FACTORY: PROPOSAL FOR THE APPLICATION OF THE SLP METHOD}

\section{Amanda L. Remondini; Bruna de O. Marcondes; Pedro Paulo L. Gomes; Rafael Medeiros Hespanhol}

${ }^{1}$ Universidade do Oeste Paulista - UNOESTE, Faculdade de Engenharia, Presidente Prudente, SP.

E-mail: amanda.remondini@hotmail.com, voehes@gmail.com

RESUMO - O presente artigo tem como objetivo abordar a importância de se propor a localização adequada e o melhor plant layout para uma fábrica de café de pequeno porte. $O$ foco deste artigo é direcionado ao planejamento da planta fabril, respeitando os padrões requeridos por órgãos governamentais. Para o dimensionamento da fábrica e determinação de seu arranjo físico, foi adotada a abordagem qualitativa no que tange a compreensão das particularidades do layout, e também a abordagem quantitativa no que se refere às informações sobre máquinas e mão de obra. Enquanto a pesquisa bibliográfica e documental deu suporte à coleta de dados. O método Systematic Layout Planning (SLP) forneceu as diretrizes para a elaboração do layout, e com o auxílio do software Autocad, a planta foi esboçada. Como resultados, espera-se que o layout desenvolvido satisfaça as reais necessidades da fábrica em estudo, de forma a atender os requisitos básicos de legislação, segurança, ergonomia e produtividade.

Palavras-chave: Projeto de fábrica. Plant layout. Fábrica de café.

ABSTRACT - This article aims to address the importance of proposing the appropriate location and the best plant layout for a small coffee factory. The focus of this article is directed to the planning of the factory plant, respecting the standards required by governmental agencies. For the sizing of the factory and determination of its physical arrangement, the qualitative approach was adopted in what concerns the understanding of the particularities of the layout, as well as the quantitative approach with regard to information on machines and labor. While bibliographical and documentary research supported the collection of data. The Systematic Layout Planning (SLP) method provided guidelines for layout design, and with the help of Autocad software, the plan was outlined. As a result, it is expected that the layout developed will meet the actual needs of the factory under study to meet the basic requirements of legislation, safety, ergonomics and productivity.

Keywords: Factory design. Plant layout. Coffee factory. 


\section{INTRODUÇÃO}

O projeto de fábrica, denominado plant design, se refere ao projeto total de um empreendimento, compreendendo inúmeros fatores decisivos para o seu sucesso, que vão desde a aplicação do capital até a localização da fábrica e planejamento dos recursos necessários para o seu funcionamento. Como parte integrante deste cenário macro, destaca-se o plant layout, que consiste no arranjo físico das instalações em um espaço previamente delimitado (OLIVERIO, 1986)

Segundo Moura (1997), o layout se trata da organização do ambiente de trabalho, devendo a disposição dos componentes existentes nesse ambiente ser cuidadosamente decidida em busca da máxima utilização das instalações, garantindo assim a adequada distribuição das áreas da organização. Em consequência disso, espera-se atingir a minimização do tempo ocioso $e$ do congestionamento do fluxo de trabalho, que por sua vez, tende a acarretar o aumento da produtividade e a redução de custos.

Para Lee (1998), o layout de uma fábrica consiste na manifestação da estratégia de produção da empresa, resultante de inúmeras decisões que influenciam na qualidade do produto e na eficiência final. Dessa forma, o layout possui extrema relevância no estudo para alcançar instalações de trabalho com bom desempenho, estas instalações se referem à prédios e equipamentos que fornecem a capacidade de agregar valor a algo e permitem que a empresa cumpra seu propósito da melhor forma possível.

\section{METODOLOGIA}

O artigo foi desenvolvido sob uma perspectiva qualitativa ao transpor para a prática os conceitos relacionados ao estudo do layout em uma fábrica e as formas de melhoria e adequação do mesmo, no entanto, a abordagem quantitativa foi utilizada no dimensionamento da capacidade de produção, assim como dos equipamentos necessários ao processo e o espaço demandado pelos postos de trabalho, considerando a rotina das operações administrativas e fabris, além das necessidades psicofisiológicas dos funcionários.

O Ministério do Trabalho e Emprego do Brasil estabelece Normas Regulamentadoras (NR) que fornecem diretrizes importantes e muitas vezes obrigatórias para a elaboração de um layout de projeto de fábrica.

Foram utilizadas como princípio norteadores do presente trabalho: NR 08, que trata das edificações; a NR 12, que se refere à segurança no trabalho em máquinas e equipamentos; a ergonomia é abordada pela NR 17; a proteção contra incêndios é tratada pela NR 23; e a NR 24 trata das condições sanitárias e de conforto nos locais de trabalho.

Destaca-se que a coleta de dados foi baseada na pesquisa bibliográfica, a fim de compreender a importância do layout e suas particularidades, enquanto a pesquisa documental foi empregada para a obtenção de especificações técnicas dos equipamentos. 0 procedimento metodológico utilizado para projetar o layout consistiu no Systematic Layout Planning (SLP). O software AutoCAD foi empregado para cumprir o objetivo de esboçar uma proposta de layout para uma fábrica de café especial, a qual delimitou o universo de estudo.

\section{ARRANJO FÍSICO (LAYOUT)}

De acordo com Figueiredo (2016), o layout é utilizado como uma ferramenta de tradução da estratégia empresarial, que estuda a melhor disposição das instalações da organização, esperando-se que esse planejamento traduza de maneira visual e tangível os aspectos importantes desta estratégia, atendendo as necessidades e peculiaridades do processo e conduzindo o seu fluxo em direção aos objetivos traçados.

Oliverio (1986) assinala os princípios que devem ser seguidos no que se refere ao projeto de layout, sendo eles: integração, onde todos os elementos devem estar em harmonia a fim de conquistar eficiência global; mínima distância, visto que as distâncias devem ser reduzidas para evitar o desperdício de esforços; obediência ao fluxo de operações, devendo ser evitados cruzamentos que interrompam o fluxo de trabalho; três dimensões, que considera não apenas a área ocupada pelos itens, mas também o volume; satisfação e segurança, pois quanto mais satisfeito o layout deixar seus usuários, melhor ele será e maior a eficiência alcançada; e flexibilidade, representado pela capacidade de mudança conforme a necessidade. 


\subsection{Abordagens de layout}

O projeto de instalações deve ser dividido conforme o nível de abrangência das atividades. No nível global é feita a seleção da região e possíveis locais para a instalação. Quanto ao nível supra, trata-se da fase de planejamento das características da construção e do local. Em relação ao nível macro, o layout se refere a determinação das células e departamentos. Em seguida, alcança-se o nível micro, em que é realizado o layout de departamento com as características das estações de trabalho. Por fim, no nível sub micro é feito o projeto das estações de trabalho. (LEE, 1998)

Lee (1998) aponta a existência de diferentes frentes de trabalho para a problemática do estudo do layout. Entre as possíveis abordagens estão: experimental, cujas instalações são planejadas com base na experiência adquirida, bom senso e extinto; plano diretor, focando nos prédios e áreas construídas, utilizando a construção para exibir força financeira e capacidade tecnológica para publicidade; clonagem, representada pela cópia de uma instalação existente ou parte dela; bottom-up, visto que a abordagem começa dos detalhes das instalações, como maquinários e pessoas para alcançar o planejamento da instalação. É ressaltada a abordagem sistemática, que emprega especialmente o Systematic Layout Planning (SLP), o qual utiliza procedimentos, fases e convenções que auxiliam nas etapas do projeto; estratégica, através da abordagem de cima para baixo, começando da estratégia de negócios para terminar no planejamento de detalhes (LEE, 1998). Nesse método, o planejamento é realizado em quatro fases: localização, arranjo físico geral, arranjo físico detalhado e implantação.

\subsection{Tipos de layout}

Almeida (2008) define os mais tradicionais de layout: funcional ou por processo, que é o tipo mais encontrado na indústria e sua principal característica é agrupar todas as operações de um mesmo tipo de processo, ou seja, as operações são organizadas de acordo com a tecnologia ou a área do conhecimento; linear, ou linha de produção, ou por produto, o material é que se move; posicional ou por posição fixa é usado para montagens complexas, em que o material ou os componentes principais ficam em um lugar fixo, sendo mais utilizado em casos voltados para projetos de grande magnitude; e layout celular, que agrupa os recursos produtivos em células independentes com o objetivo de melhorar o gerenciamento do sistema de manufatura (CHINATO, 1998 apud DALMAS, 2004).

\section{RESULTADOS E DISCUSSÃO}

A localização, que se refere a primeira etapa do método, foi estabelecida no subúrbio do município de Manhuaçu, no estado de Minas Gerais. O subúrbio foi escolhido por dispor de espaço para possíveis expansões futuras e por estar próximo aos grandes centros e seus recursos, evitando ainda que o processo produtivo cause incômodo na população, em decorrência de fatores como ruído e poluição atmosférica. O local definido para instalação da fábrica se refere a um terreno de dimensões de 74 metros de largura por 57 metros de comprimento, situado em um distrito industrial à beira da rodovia BR 262, permitindo assim o fácil acesso de veículos.

0 processo produtivo que envolve este produto é conhecido e abrange as etapas de inspeção e recebimento de matéria-prima (MP), torrefação dos grãos, moagem, inspeção do produto processado, embalagem do pó de café, e estocagem do produto acabado (PA).

A capacidade de produção se deu a partir da escolha dos equipamentos, que basicamente são torrador, moinho e empacotadora, além de transportadores, como elevadores pneumáticos e esteiras.

O torrador selecionado possui curva de torra rápida e eficaz, controle automático de chama modulante, velocidade de ar quente e rotação de cilindro. A máquina ainda é dotada de sistema de resfriamento super eficiente, sistema automatizado para operacionalização dos ciclos de torra, além de dispor de um sistema limpante das tubulações e baixíssimo nível de ruído. 0 sistema é econômico e ecológico, sendo isento de fumaça. A capacidade produtiva da máquina corresponde a $950 \mathrm{~kg} / \mathrm{hora}$. Suas dimensões de largura, comprimento e altura, são de $3500 \mathrm{~mm} \mathrm{x}$ $7000 \mathrm{~mm} \times 4000 \mathrm{~mm}$, respectivamente.

O moinho possui sistema de quebradores com vida útil extensa e proporciona uma moagem com granulometria uniforme. A capacidade produtiva da máquina é de 600 $\mathrm{kg} / \mathrm{hora}$. Suas dimensões de largura, comprimento e altura, correspondem a $1280 \mathrm{~mm}$ x $3250 \mathrm{~mm}$ x $3000 \mathrm{~mm}$, respectivamente. A empacotadora automática para café moído é 
indicada para torrefações de qualquer porte. Possui sistema e dosagem especial para moído e formatação para pacotes em almofada ou pouch com válvula, com capacidade de produzir 40 pacotes de 250 gramas por minuto, o que totaliza $600 \mathrm{~kg} / \mathrm{hora}$. Suas dimensões de largura, comprimento e altura, correspondem a $600 \mathrm{~mm} \mathrm{x}$ $680 \mathrm{~mm} \times 1600 \mathrm{~mm}$, respectivamente.

A segunda etapa do método SLP foi determinada a partir da disposição do setor fabril, armazéns, setor administrativo, estacionamento para funcionários, pátio para caminhões, balança, pontos de carga e descarga, vestiários e sanitários, além de áreas destinadas à circulação de pessoas e manobra de veículos. Destaca-se que um espaço de oito metros foi deixado livre entre as limitações da fábrica e o muro que separa a propriedade da área externa, além de uma calçada após o muro, de modo a garantir uma distância relevante da rodovia.

$O$ arranjo detalhado, referente à terceira etapa do SLP, primeiramente ocorreu por meio da determinação dos departamentos do setor administrativo, sendo eles: diretoria; faturamento; contabilidade; logística; financeiro e fiscal; compras; recursos humanos; vendas e marketing; e planejamento e controle da produção, sendo que este último foi alocado no prédio fabril, diferentemente dos demais que pertencem a um prédio específico. A área fabril foi determinada pela disposição das máquinas no espaço destinado à produção de acordo com suas dimensões, reservando um espaço apropriado para sua operação, manutenção, limpeza, e segurança dos funcionários, além da movimentação de pessoas e materiais, conforme a NR 12.

Anexos ao edifício fabril, encontram-se os armazéns de matéria-prima e produto acabado, onde ocorre, respectivamente, o recebimento e o carregamento de produtos. Sendo assim, há um espaço específico destinado ao armazenamento de materiais, atendendo também a NR 12. Além disso, há um laboratório de análise de qualidade das amostras tanto de matéria-prima quanto de produto acabado, que tem acesso direto à fábrica e está localizado entre os dois armazéns. Foram demarcadas faixas de pedestre para a circulação segura dos funcionários, tanto para o acesso ao escritório quanto à fábrica, inclusive no interior da fábrica. Este espaço de segurança pode ser utilizado no caso de eventuais visitas técnicas, de modo a garantir que os visitantes fiquem longe $o$ suficiente do processo produtivo e das situações de risco com alto potencial de acidentes.

Conta-se ainda com um espaço destinado à portaria e uma balança rodoviária para pesagem das mesmas, localizada próximo ao pátio de caminhões. A balança possui capacidade para no máximo um caminhão popularmente chamado de truck, cujas dimensões de largura, comprimento e altura, são, respectivamente, $2600 \mathrm{~mm} \times 16000 \mathrm{~mm} \times 4400 \mathrm{~mm}$. A capacidade de carga líquida deste veículo varia entre 14 e 15 toneladas. O pátio possui capacidade para o estacionamento de dois trucks. Sendo assim, veículos de menor porte também serão acessíveis.

Há a disponibilidade de sanitários em todos os prédios, cujas áreas são superiores ao que é considerado como mínimo pela NR 24. Destaca-se que antes de adentrar a área de produção, há uma barreira sanitária que deve ser utilizada pelos operários para higienização das mãos e antebraços. De acordo com as diretrizes da NR 12, os quadros de energia terão acesso restrito e sinalização de choque elétrico.

Conforme a NR 08, todos os ambientes disporão de cobertura contra chuva, a iluminação será feita de forma artificial, no entanto, os espaços serão dotados de janelas para complementação com luz natural, com exceção da fábrica, que não terá janelas, mas em vez disso, contará com placas transparentes no teto.

Tendo em vista a NR 17, os painéis das máquinas proporcionarão ao trabalhador condições de boa postura. A área fabril e a disposição das atividades permitirão o posicionamento e movimentação adequada das pessoas e dos materiais.

Atendendo a requisitos da NR 23, todos os ambientes dispõem de saídas para o ambiente externo, e a fábrica, local mais propício a focos de incêndio, dispõe de uma saída de emergência, visto que o acesso pela saída convencional é mais difícil por ter desvios e passar por outros setores. Além disso, conta-se com a instalação de um hidrante nas proximidades da fábrica para combater possíveis incêndios.

A Figura 4 apresenta a planta baixa da proposta de layout para a fábrica de café especial. 
Figura 3. Planta baixa da fábrica de café

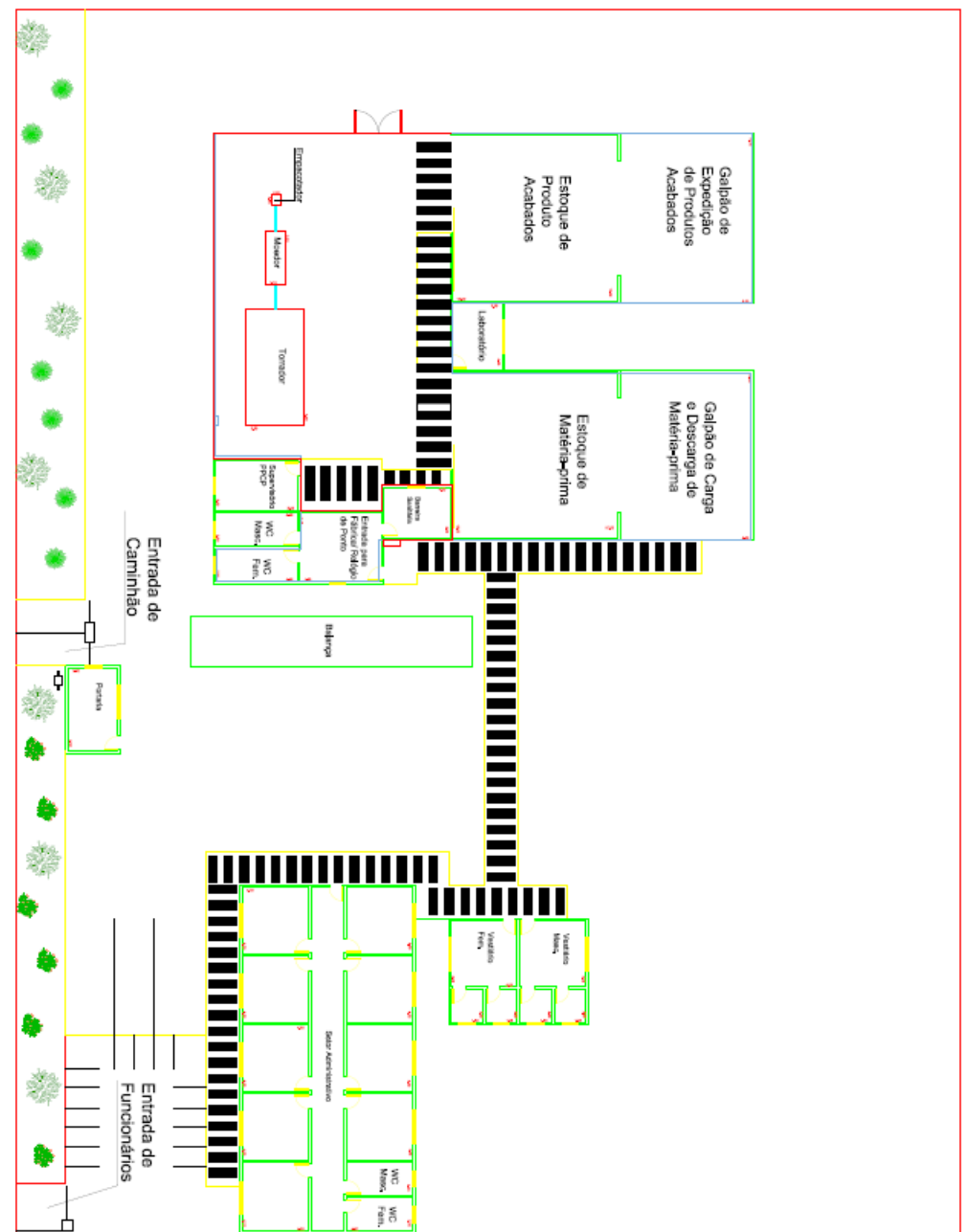

Fonte: Elaborado pelos próprios autores (2018).

Observa-se que o tipo de layout empregado é do tipo combinado ao considerar toda a extensão do terreno, visto que o setor administrativo está organizado segundo o arranjo físico funcional, e a fábrica, por sua vez, segue um arranjo físico linear ou por produto, em que a disposição dos locais de trabalho obedece a sequência de processamento do café (torrefação, moagem e embalagem). Dando ênfase ao setor fabril, o layout escolhido se justifica pelo fato das máquinas serem interligadas através de sistemas transportadores, sendo que uma etapa é dependente de sua antecessora.

Os gargalos da produção são o moinho e a empacotadora, sendo assim, a fábrica operará no máximo de acordo com a capacidade dessas máquinas. Porém, caso haja aumento de demanda, há espaço disponível para a alocação de máquinas extras para essas operações, ou até mesmo de uma segunda linha de produção, permitindo assim a expansão da fábrica devido a futuras necessidades. É importante ressaltar que o espaço ocupado pelo equipamento desligado ou em operação é o mesmo, sendo assim o funcionamento da máquina não impacta o espaço disponível para a circulação dos trabalhadores e materiais.

\section{CONSIDERAÇÕES FINAIS}

O artigo apresentou brevemente a importância do planejamento de layout em uma fábrica, os tipos e métodos existentes para a sua elaboração, além das legislações a serem obedecidas. Com este estudo constata-se que o layout de uma fábrica envolve a definição de diversos detalhes que devem ser cuidadosamente analisados para atingir a eficiência e a eficácia, evitando dificuldades, limitações e retrabalhos no futuro.

Buscou-se integrar harmonicamente as atividades relacionadas; minimizar as distâncias entre as operações subsequentes; o processo produtivo permitiu a obediência ao fluxo de operações; o layout foi projetado considerando a perspectiva tridimensional, mesmo que a terceira 
dimensão não tenha sido ilustrada; foram observados fatores para a promoção da segurança e do conforto dos trabalhadores; e a fábrica esboçada possui flexibilidade para alterações, tanto no que se refere à adoção de novas tecnologias quanto à expansão da linha de produção, visto que o espaço interno é amplo.

\section{REFERÊNCIAS}

ALMEIDA, Sheila Souza de. Otimização de Layout de Plantas Químicas Utilizando o Problema de Designação Quadrática. 2008. 167 f. Dissertação (Mestrado) - Curso de Mestrado em Engenharia Química, Universidade Estadual de Campinas, Campinas-SP, 2008. Disponível em: <http://repositorio.unicamp.br/bitstream/REPOSI $\mathrm{P} / 267187 / 1 /$ Almeida_SheilaSouzade_M.pdf $>$. Acesso em: 01 maio 2018.

BRASIL. Ministério do Trabalho e Emprego. NR 08 - EDIFICAÇõES. Brasília: Ministério do Trabalho e Emprego, 1978. Disponível em: <http://trabalho.gov.br/images/Documentos/SST /NR/NR8.pdf>. Acesso em: 02 maio 2018.

BRASIL. Ministério do Trabalho e Emprego. NR 12 - SEGURANÇA NO TRABALHO EM MÁQUINAS E EQUIPAMENTOS. Brasília: Ministério do Trabalho e Emprego, 1978. Disponível em: <http://www.trabalho.gov.br/images//Document os/SST/NR/NR12/NR-12.pdf>. Acesso em: 02 maio 2018.

BRASIL. Ministério do Trabalho e Emprego. NR 17 - ERGONOMIA. Brasília: Ministério do Trabalho e Emprego, 1978. Disponível em: <http://trabalho.gov.br/images/Documentos/SST /NR/NR17.pdf>. Acesso em: 02 maio 2018.

BRASIL. Ministério do Trabalho e Emprego. NR 23 - PROTEÇÃO CONTRA INCÊNDIOS. Brasília: Ministério do Trabalho e Emprego, 1978.

Disponível em:

<http://trabalho.gov.br/images/Documentos/SST /NR/NR23.pdf>. Acesso em: 02 maio 2018.

BRASIL. Ministério do Trabalho e Emprego. NR 24 - CONDIÇÕES SANITÁRIAS E DE CONFORTO NOS LOCAIS DE TRABALHO. Brasília: Ministério do Trabalho e Emprego, 1978. Disponível em: <http://trabalho.gov.br/images/Documentos/SST /NR/NR24.pdf>. Acesso em: 02 maio 2018.
COSTA, Adriano José. Otimização do layout de produção de um processo de pintura de ônibus. 2004. 123 f. Dissertação (Mestrado) Curso de Mestrado Profissionalizante em Engenharia, Universidade Federal do Rio Grande do Sul, Porto Alegre, 2004. Disponível em: <http://www.lume.ufrgs.br/handle/10183/5277> . Acesso em: 01 maio 2018.

DALMAS, Volnei. Avaliação de um layout celular implementado: um estudo de caso em uma indústria de autopeças. 2004. 133 f. Dissertação (Mestrado) - Curso de Mestrado

Profissionalizante em Engenharia, Universidade Federal do Rio Grande do Sul, Porto Alegre, 2004. Disponível em:

<http://www.lume.ufrgs.br/handle/10183/4626> . Acesso em: 03 maio 2018.

FIGUEIREDO, Luís Henrique W. Aplicação dos tipos de layout: uma análise da produção científica. 2016. 57 f. Trabalho de Conclusão de Curso (Graduação) - Curso de Engenharia de Produção, Universidade de Brasília, Brasília, 2016. Disponível em:

<http://bdm.unb.br/bitstream/10483/15208/1/2 016_LuisHenriqueWanderleydeFigueiredo_tcc.pd f>. Acesso em: 01 maio 2018.

LEE, Quarterman. Projeto de instalações e do local de trabalho. São Paulo: Imam, 1998

MOURA, Reinaldo A. Manual de logística: Armazenagem e distribuição física. 2. ed. São Paulo: Imam, 1997.

OLIVERIO, José Luiz. Produtos, processos e instalações industriais. São Bernardo do CampoSP: Ivan Rossi, 1986).

RIBEIRO, Antônio Clélio; PERES, Mauro Pedro; IZIDORO, Nacir. Desenho técnico e AutoCAD. São Paulo: Pearson Education do Brasil, 2013.

Disponível em:

<http://unoeste.bv3.digitalpages.com.br/users/p ublications/9788581430843/>. Acesso em: 01 maio 2018.

SOUZA, Livia L. Alves; AMORIM, Sérgio R. Leusin; LYRIO, Arnaldo M. Impactos do uso do BIM em escritórios de arquitetura: oportunidades no mercado imobiliário. Gestão \& Tecnologia de Projetos, v. 4, n. 2, p. 26-53, 2009. 